\title{
IMPLEMENTAÇÃO COMPARTICIPADA DE MEDIDAS ESTRUTURANTES NA LITIGÂNCIA DE INTERESSE PÚBLICO PARA TUTELA DE DIREITOS FUNDAMENTAIS
}

\author{
Luciana Cecília Morato ${ }^{1}$ \\ Helena Patrícia Freitas ${ }^{2}$
}

RESUMO: Com o fortalecimento do movimento de litigância de interesse público a partir de da década de cinquenta nos Estados Unidos, houve uma mudança na concepção da função jurisdicional, ocasionada por reformas legislativas, paradigmáticas decisões judiciais e crescimento dos estudos sobre litígio de direito público. Portanto, a mera proposição de procedimentos para criação e/ou execução de política pública pela via jurisdicional não é, há muito, suficiente à efetiva tutela de direitos fundamentais, motivo pelo qual, este trabalho propõe, formas de implementação de medidas estruturantes na litigância de interesse público para que haja reforma estrutural de entes públicos através da função jurisdicional.

PALAVRAS-CHAVE: Medidas estruturantes. Litigância de interesse público. Comparticipação. Policentrismo. Direitos Fundamentais.

\section{COMPARTICIPATIVE IMPLEMENTATION OF STRUCTURAL INJUNCTIONS IN PUBLIC INTEREST LITIGATION FOR PROTECTION OF FUNDAMENTAL RIGHTS}

\begin{abstract}
With the strengthening of the public interest litigation movement since the 1950s in the United States, there has been a change in jurisdictional functions, brought about by legislative reforms, paradigmatic court decisions, and the growth of studies on public law litigation. Therefore, a mere proposition of procedures for the creation and / or execution of public policy through the courts is not long enough to effect protection of fundamental rights, which is why, this work performed, forms of execution of measures structured in the litigation of public interest for structural reform of public inputs through the jurisdictional function.
\end{abstract}

KEYWORDS: Structural Injunctions. Public interest litigation. Comparticipation. Policentrism. Fundamental Rights.

\section{CONSIDERAÇÕES INICIAIS}

Até meados do século XX, nos Estados Unidos da América, majoritariamente, prevaleceu uma concepção de função jurisdicional pautada nas premissas do liberalismo

\footnotetext{
${ }^{1}$ Mestre em Direito Processual pela PUC/MG. Professora em Cefet/MG. Advogada.

lucianaceciliamorato@hotmail.com

${ }^{2}$ Doutoranda em Direito Processual pela PUC/MG. Mestre em Direito Processual pela PUC/MG. Professora em PUC/MG. Advogada. helenapfreitas@gmail.com
} 
jurídico, em que o procedimento jurisdicional era espaço bipolarizado, onde parte privadas buscavam solucionar controvérsias singulares acerca de direitos eminentemente privados e o decisor atuava mediante postura passiva, adstrita exclusivamente às alegações suscitadas pelos litigantes.

Entretanto, da década de cinquenta em diante, em decorrência de uma conjuntura de reformas legislativas e prolação de paradigmáticas decisões judiciais pela Suprema Corte norteamericana, em consonância com os preceitos do Estado de Bem Estar Social e em uma conjuntura pós "New Deal", houve um crescimento exponencial da preocupação jurídica em relação à tutela de direitos fundamentais que importasse em ingerência da função jurisdicional nas instituições públicas, principalmente no que tange à criação e/ou implementação de políticas públicas.

Assim, em decorrência da adoção judicial do modelo de socialização processual verificou-se na confederação estadunidense, o surgimento de um novo tipo de litigiosidade denominado "litigância de interesse público", preocupado com um procedimento jurisdicional prospectivo, plurilateral, mediante cooperação processual e diálogos interinstitucionais, com repercussões complexas e sedimentado sob preceitos de atuação protagonista do decisor mas, ao mesmo tempo, com pronunciamentos decisórios construídos em comparticipação ${ }^{3}$.

Importantes pesquisas acadêmicas foram realizadas em direção ao fortalecimento do movimento do litígio de direito público, com proposições sob óticas gerenciais, transacionais, dialógicas, experimentalistas e reformistas, objetivando dar emergente modelo de litigiosidade identificado um constante aprimoramento, para que, dessa forma, os mecanismos processuais utilizados na litigância de interesse público pudessem proporcionar uma tutela efetiva, cognitiva e executiva, do direito fundamental clamado em juízo.

Assim, propondo um modelo jurisdicional que objetivava não somente a resolução de controvérsias concernentes à litigância de interesse público, mas que, fosse capaz de promover uma reforma estrutural nas instituições públicas, o estadunidense Owen Fiss, capitaneou pesquisa acerca das "structural injunctions".

A concepção de um procedimento jurisdicional capaz de promover uma reforma estrutural das instituições públicas surgiu, justamente, em decorrência do afastamento do

\footnotetext{
3 “O principal fundamento da comparticipação é o contraditório como garantia de influência e não surpresa”. Cf. THEODORO JÚNIOR, Humberto et al., 2015.
} 
modelo processual liberal, adoção dos pressupostos inerentes à litigância de interesse público e, ainda, na falsa crença do protagonismo judicial advindo da socialização processual.

Entretanto, em que pese o ativismo judicial ter sido visto, à época, como um avanço em relação à ótica do modelo processual liberal, porquanto àquele superava a problemática em torno da postura passiva do juiz/tribunal, a herança da adoção da socialização processual trouxe uma grande problemática à jurisdição, consistente no protagonismo judicial.

Crer que o decisor possui uma capacidade virtuosa para fixar medidas estruturantes sem nenhum tipo de embasamento normativo e limitação à sua atuação, é deixar uma porta aberta à arbitrariedade judicial, que não possui espaço dentro de um Estado Democrático de Direito.

O Código de Processo Civil Brasileiro de 2015 dá, pelo menos em um plano introdutório, embasamento normativo para que o decisor possa, após efetivo contraditório, diálogo interinstitucional e em comparticipação, prolatar decisão estruturante, prospectiva e com aprimoramento continuado, que seja apta e promover uma reforma nas instituições públicas.

Dessa forma, o presente artigo se propõe a descrever o movimento da litigância de interesse público, fortalecido a partir da década de cinquenta nos Estados Unidos da América, a partir do câmbio da concepção acerca do objetivo da função jurisdicional e, como o litígio de direito público pode ser implementado para que seja promovida uma efetiva reforma estrutural nas instituições públicas, oferecendo, para tanto, base normativa ao decisor para que não caia na sedução do protagonismo judicial.

\section{MOVIMENTOS DE LITIGÂNCIA DE INTERESSE PÚBLICO}

O fenômeno da litigância de interesse público não surgiu da noite para o dia, sendo o atual estado da arte - embora ainda não esteja em seu mais alto nível de desenvolvimento fruto de um processo de busca epistemológica sobre a temática pela legislação, jurisdição e Academia, desde o início do século XX, nos Estados Unidos da América, a fim de que os direitos fundamentais pudessem ser tutelados sob uma nova ótica, mais comparticipada, inclusiva e democrática. 
Há muito prevaleceu a proposição de Lon Luvois Fuller acerca da função, formas e limites da prestação da atividade jurisdicional, através do academicamente denominado "modelo tradicional de jurisdição" (FULLER, 1978).

Conforme a concepção de Fuller, a jurisdição é uma forma de ordenação social por reciprocidade dotada de racionalidade e que se diferencia de todas as demais formas de organização societária na medida em que, na função jurisdicional, os litigantes podem apresentar provas e argumentos fundamentados acerca de suas alegações.

Contudo, a visão de Fuller acerca da jurisdição é limitada a um processo bipolar, retrospectivo, compensatório, terminativo, com atuação judicial passiva e adstrita ao suscitado pelas litigantes, onde partes privadas travam verdadeira batalha acerca de direitos eminentemente privados.

Assim, o modelo tradicional de jurisdição não se propõe a resolver problemas policêntricos e plurilaterais porquanto não é função da jurisdição interferir em questões que importem em repercussões complexas e atinjam partes não envolvidas no litígio.

Entretanto, verifica-se que o estudo acerca da proposição do modelo adjudicatório tradicionalista, publicado postumamente em 1978, de Lon Luvois Fuller, ganhou notoriedade quando já defasado, isso porque em 1875, quase um século antes, a jurisdição dos tribunais federais em relação aos estaduais foi ampliada através do Act of March 3 e, consequentemente, houve uma avolumação de casos levados à apreciação pelas cortes federais, mostrando, assim, os primeiros sinais em direção a uma mudança acerca da concepção da função jurisdicional.

Em que pese o artigo publicado por Fuller ter sido publicado já relativamente idoso, a concepção tradicionalista possuiu, e ainda os têm na contemporaneidade, expressivo número de discípulos que propagam suas proposições, sendo o modelo, inclusive, background de diversos enunciados legislativos e pronunciamentos judiciais no ordenamento jurídico brasileiro.

Sob outra ótica, ancorado em um contexto de significantes mudanças legislativas e paradigmáticas decisões judiciais proferidas pela Suprema Corte Norteamericana, Abraham Chayes identificou um emergente tipo de litigiosidade ao qual denominou "Public Law Litigation" no qual, diferentemente do modelo tradicional de jurisdição, o processo é plurilateral, prospectivo, continuado, com atuação judicial ativa, flexibilização da adstrição e com intuito de discutir judicialmente uma política pública. (CHAYES, 1976) 
A exemplo, o arquétipo precedente "Brown vs Board of Education of Topeka" foi o pronunciamento jurisdicional com repercussões mais complexas na década de cinquenta a setenta nos Estados Unidos da América e cambiou em peso a noção acerca da função da jurisdição.

Em suma, saturados da doutrina do "separate but equal", difundida nos Estados Unidos da América pela decisão proferida em "Plessy vs Ferguson", de 1896, a partir da reunião de cinco ações coletivas, “crianças negras pleiteavam, por meio de seus representantes legais, a admissão em escolas públicas primárias ou secundárias em um regime livre de segregação racial"(GARCIA, 2017), a fim de que obtivessem acesso à mesma qualidade de ensino oferecida às crianças brancas.

Assim, "ao superar (overruling) o precedente que cristalizara a doutrina dos 'separados mas iguais' nas relações entre brancos e negros, e proibir a existência de escolas segregadas naquele país" (THEODORO JÚNIOR et al., 2013), a decisão judicial proferida em "Brown vs Board of Education of Topeka" pela Corte Warren foi um verdadeiro marco no que tange à concepção da função da jurisdição e sondado por Abram Chayes, para que pudesse compor o protótipo ${ }^{4}$ do emergente modelo de litigiosidade de direito público.

Da mesma maneira, as emendas legislativas de 1966 às Regras Federais de Processo Civil dispuseram sobre questões relevantes, como a intervenção de terceiros e as "class actions" e, ainda, em decorrência da eclosão das "injunctions" perante a jurisdição norteamericana, verificou-se uma significável mudança doutrinária e jurisprudencial acerca da concepção sobre o objeto e limites da função jurisdicional, nos moldes do emergente tipo de litigiosidade identificado por Chayes, denominado litigância de direito público.

A partir daí, verifica-se que a maioria dos estudos nos Estados Unidos da América acerca da função jurisdicional embasava-se no novo modelo de litigiosidade identificada, qual seja, o de direito público e, ao longo da década de setenta até o final dos anos dois mil, o que ocorreu foi uma verdadeira metamorfose do movimento denominado "Public Law Litigation" porquanto cresceu demasiadamente, tornando-se objeto de incessante busca epistemológica da Academia em diversos países.

Propondo um processo consultivo, Melvin Eisenberg traz à tona um modelo jurisdicional em que o juiz/tribunal deve se atentar aos fatos e argumentos suscitados pelos

\footnotetext{
${ }^{4}$ Em que pese o artigo de Abram Chayes, publicado em 1976, ter alcançado grande louvor acadêmico, o autor, à época, considerava o estudo apenas como um protótipo, a ser estudado e ampliado por seus sucessores. Cf. CHAYES, 1976.
} 
litigantes e proferir decisões fundamentadas, entretanto, a responsividade do pronunciamento jurisdicional para com o arguido pelos litigantes é flexibilizada, a fim de que sejam sanadas, pelo juiz/tribunal, as possíveis deficiências não arguidas pelas partes (EISENBERG, 1978).

Em que pese não propor nenhum modelo jurisdicional, Judith Resnik desenvolveu importante estudo crítico acerca do fenômeno de utilização de técnicas de gerenciamento negocial pelos tribunais para dimensionamento de conflitos, em decorrência do aumento exponencial de demandas judiciais e, ainda, verificou uma verdadeira deturpação das audiências "pretrial", utilizadas, então, anomalamente, como procedimento para dar vazão a processos (RESNIK, 1982).

Fazendo críticas similares àquelas efetuadas por Resnik, acerca da má utilização das técnicas de gestão nos processos jurisdicionais, Donald L. Horowitz desenvolve pesquisa às origens, características e consequências da supervisão judicial das instituições públicas norte americanas, verificando, que tal controle deve se dar através de pronunciamentos jurisdicionais que importem em uma mudança organizacional das instituições, chamando atenção, entretanto, para o cuidado que deve se ter a fim de que ao decisor não sejam atribuídos poderes desmesurados (HOROWITZ, 1983).

Batendo às portas do século XXI, Linda Mullenix, chamou atenção ao tipo de litigiosidade denominado "mass tort litigation", que, segundo a Autora, se trata de verdadeira privatização do modelo de litigiosidade de direito público proposto por Chayes, porquanto possui características semelhantes ao modelo chayesiano, entretanto tutela, também, direitos individuais. Em suma, o "mass tort" é a litigância em massa, podendo ser individual ou coletiva, abarcando as espécies "class action", destinada a salvaguardar direitos difusos e coletivos stricto sensu e a "multidistrict litigation", procedimento que visa tutelar direitos individuais homogêneos (MULLENIX, 1999).

George Rubenstein, em que pese reconhecer que as Emendas de 1966 às Regras Federais de Processo Civil dos Estados Unidos da América representaram significável influência na concepção de jurisdição como o tinham á época, em 2001, afirma que as proposições em torno da litigância de interesse público restarão infrutíferas se não reimaginadas sob uma ótica transacional entre as partes, afirmando, inclusive, a necessidade da uma reinvenção das "class actions" a fim de que possuam mais elementos encorajadores à composição (RUBENSTEIN, 2001). 
Alvitrando uma interessante vertente, Rosalind Dixon traz à tona um modelo jurisdicional ao qual denomina de dialógico, incentivador de diálogos interinstitucionais entre as funções legislativa e jurisdicional, para efetivação de direitos fundamentais/socioeconômicos, através da revisão judicial de pontos cegos e/ou encargos de inércia do processo legislativo (DIXON, 2007).

Por sua vez, através de uma concepção eminentemente programática e cooperativa da função jurisdicional, Charles Sabel e William Simon elaboraram proposição experimentalista, na qual são eleitas normas para revisão judicial da decisão prolatada, após o crivo do efetivo contraditório, com constantes mutações em direção a um aperfeiçoamento do pronunciamento jurisdicional, abrindo a caixa preta das instituições públicas e promovendo um diálogo endoprocessual horizontal entre entes privados, públicos, assistentes, terceiros e agentes extrajudiciais - afastando-se, primordialmente, da ótica sancionatória governamental, principalmente no que tange à fase executiva do procedimento jurisdicional e caminhando sempre rumo a uma ótica experimentalista (SABEL e SIMON, 2004).

Ainda, há de se falar no modelo catalítico proposto por Katharine Young, denominado dessa maneira em decorrência da analogia feita pela autora com o processo de catálise, importado da química. Conforme a proposição de Young, os vários tipos de modelos jurisdicionais até então vistos, formam, juntos, um único modelo jurisdicional, o catalítico e, a depender do caso em questão, a atuação da corte deverá "catalisar" uma das características dos modelos até então expostos, para, através da característica catalisada, buscar um pronunciamento jurisdicional em menor tempo. Assim, um mesmo procedimento jurisdicional pode apresentar características gerenciais, transacionais ou experimentalistas, mas, cabe ao decisor escolher qual atributo será capaz de catalisar uma solução efetiva e célere apta a findar o procedimento (YOUNG, 2010).

Dessa forma, verifica-se que a mudança na noção do objeto da função jurisdicional, no que tange à litigância de direito público, possui tímidas aparições legislativas desde o século XIX e caminhou a passos largos rumo ao estado da arte aferido na contemporaneidade, principalmente a partir de meados da década de cinquenta, em um contexto de reformas legislativas e paradigmáticos pronunciamentos jurisdicionais, em que ganhou “(...) destaque a percepção de direitos metaindividuais, que forçaram a jurisdição a atuar em demandas moleculares, mediante técnicas processuais coletivas (...)" (THEODORO JÚNIOR et al., 
2013) e ainda, em decorrência do empenho jurisdicional no dimensionamento do litígio de interesse público, com decisões, desejavelmente, qualitativas e quantitativas.

\section{MEDIDAS ESTRUTURANTES}

A conjuntura dos Estados Unidos da América em meados do século XX, que se encontrava imerso no paradigma do Estado de Bem Estar Social, foi marcada por um crescimento exponencial da preocupação com os direitos sociais e consequente afastamento das premissas do liberalismo jurídico.

O histórico de reformas legislativas e paradigmáticas decisões judiciais como -

conforme já mencionados - as Emendas às Regras Federais de Processo Civil de 1966, a eclosão das "civil injunctions" e "class actions" e massivo impacto do precedente dessegregacionista de "Brown vs Board of education of Topeka" e, ainda, a eclosão de estudos acadêmicos em torno da temática, levaram à ascensão do tipo de litigiosidade identificado como litigância de interesse público.

Entretanto, o processo jurisdicional é um procedimento dialógico e comparticipado que objetiva tutelar direitos fundamentais em sua inteireza, motivo pelo qual, a função da jurisdição não deve ser a de simplesmente solucionar controvérsias, de entes públicos ou privados, mas sim, em verdade, a partir de um pronunciamento jurisdicional construído mediante o crivo de efetivo contraditório, atentando-se à importância dos diálogos institucionais, sob uma ótica experimentalista, prospectiva e em contínuo aprimoramento, seja a função jurisdicional capaz de promover uma reforma estrutural das instituições públicas.

Considerando que há uma inoperância crônica na criação e execução de políticas públicas pelas funções legislativa e executiva, ofertar ao jurisdicionado um procedimento para que pleiteie judicialmente a tutela de direitos fundamentais, sem que se descubra a causa efetiva do problema, ou sejam projetados métodos para tentar evitá-lo, é dar solução atomizada a uma incorreção molecular. O simples acesso à "injunction" não é suficiente. Só o será, se a injunção for capaz de promover uma reforma estrutural, sob pena de frustração na execução da decisão judicial prolatada em sede de litigância de interesse público.

A "structural reform", proposição do norteamericano Owen Fiss e estudada no Brasil por Marco Jobim Félix sob o título de "medidas estruturantes", é fruto da epistemologia dos 
estudos acerca do litígio de direito público, configurada com um passo adiante até o que se entendia sobre tal temática.

Owen Fiss não dá conceito analítico do que seja uma decisão estrutural, entretanto, tal pronunciamento jurisdicional pode ser definido da seguinte maneira:

A decisão estrutural (structural injunction) é, pois, aquela que busca implantar uma reforma estrutural (structural reform) em um ente, organização ou instituição, com o objetivo de concretizar um direito fundamental, realizar uma determinada política pública ou resolver litígios complexos. Por isso, o processo em que ela se constrói é chamado de processo estrutura. Parte-se da premissa de que a ameaça ou a lesão que as organizações burocráticas representam para a efetividade das normas constitucionais não pode ser eliminada sem que tais organizações sejam reconstruídas. (DIDIER JR. et al., 2017)

Fiss singulariza o procedimento judicial que colima alcançar uma reforma estrutural, afirmando que "na adjudicação voltada à resolução de controvérsias pressupõe-se que a sociedade é harmoniosa perturbada por fatos isolados aos quais o Judiciário deve se reportar investigando e decidindo para garantir a pré-existente harmonia." (SILVEIRA, 2007) enquanto, diferentemente, o foco da "structural reform", não são fatos isolados que, perturbariam a utópica harmonia social padrão, porquanto a questão principal do processo que objetiva promover uma reforma estrutural é "uma condição social que ameaça importantes valores constitucionais e a dinâmica organizacional que cria e perpetua tal condição" (FISS, 1979).

Assim, verifica-se que a proposição de Fiss não busca tão somente aprimorar o processo jurisdicional que envolva entes públicos a fim de dar uma solução efetiva ao caso que diga respeito à litigância de interesse público. Claro, isso é almejado. Entretanto, mais que isso, Fiss apresenta um novo modelo de jurisdição, intentado a promover transformações nas instituições públicas, em que a função estatal jurisdicional é colocada “(...) diante dos valores públicos como protagonista, por meio de um ativismo judicial equilibrado para servir de alerta aos demais poderes para que estes, efetivamente, cumpram suas atribuições" (JOBIM, Marco Félix et al., 2017). 
O modelo de reforma estrutural é fruto do proposto pelo "Public Law Litigation" de Chayes, porquanto ambos são procedimentos prospectivos, plurilaterais, continuados ${ }^{5}$, com flexibilização da adstrição e congruência, repercussões complexas e submetidos ao crivo da ampla participação e efetivo contraditório. Todavia, a "structural reform" se destaca por, justamente, atribuir à função jurisdicional uma função promotora reformista de instituições públicas, a partir de "uma nova forma de adjudication na qual os valores constitucionais são preenchidos pelos juízes que, conscientes da estrutura burocratizada do Estado, devem apontar soluções para a efetividade da decisão judicial” (FÉLIX, Marco Jobim, 2013).

Todavia, ao tentar mitigar as burocracias estatais e dar significado aos valores públicos, quando se trata da litigância de interesse público, face à inoperância das demais funções estatais, inevitavelmente, a jurisdição age mais ativamente para criar/executar políticas públicas, sem que isso configure, no entanto, usurpação de competência.

O próprio Fiss confessa que existem problemas no modelo jurisdicional de reforma estrutural que não podem ser facilmente descartados (FISS, 1979), isso porque o juiz/tribunal encontra-se dividido entre "o mundo ideal e o mundo da prática, o mundo do valor público e o mundo da preferência subjetiva, o mundo da Constituição e o mundo das políticas" (FISS, 1979).

A questão de grande preocupação concerne à arbitrariedade e protagonismo judiciais $^{6}$, ao crer o decisor que possui uma qualidade virtuosa para fixar as medidas

\footnotetext{
${ }^{5}$ Sobre o contínuo aprimoramento das decisões estruturais, denominados de "provimentos em cascata", afirma Sérgio Cruz Arenhart: "Por outro lado, é muito frequente no emprego de medidas estruturais a necessidade de se recorrer a provimentos em cascata, de modo que os problemas devam ser resolvidos à medida que apareçam. Assim, por exemplo, é típico das medidas estruturais a prolação de uma primeira decisão, que se limitará a fixar em linhas gerais as diretrizes para a proteção do direito a ser tutelado, criando o núcleo da posição jurisdicional sobre o problema a ele levado. Após essa primeira decisão - normalmente, mais genérica, abrangente e quase "principiológica", no sentido de que terá como principal função estabelecer a "primeira impressão" sobre as necessidades da tutela jurisdicional - outras decisões serão exigidas, para a solução de problemas e questões pontuais, surgidas na implementação da "decisão-núcleo", ou para a especificação de alguma prática devida. Possivelmente, isso se sucederá em uma ampla cadeia de decisões, que implicarão avanços e retrocessos no âmbito de proteção inicialmente afirmado, de forma a adequar, da melhor forma viável, a tutela judicial àquilo que seja efetivamente possível de se lograr no caso concreto. Não raras vezes, esses provimentos implicarão técnicas semelhantes à negociação e à mediação. Cf. ARENHART, 2015.

${ }^{6}$ Myriam Gilles afirma haver um grande desconforto, ocasionado por razões políticas, quanto ao ativismo judicial. Isso porque, segundo a Autora, o medo é justamente de que os juízes envolvidos na reforma estrutural substituam, indevidamente, seus próprios pontos de vista, pelo de funcionários e cidadãos dentro da instituição ou comunidade infratora. No original: In particular, the structural reform injunction has disappeared from the contemporary sociolegal landscape because of the essentially political fear of judicial activism. The concern is that judges engaged in structural reform improperly substitute their own views for those of officials and citizens within the offending institution or community. Cf. GILLES, 2003.
} 
estruturantes, com especial receio quanto ao cenário jurídico brasileiro, face às inúmeras aberrações cometidas diuturnamente em todas as esferas estatais.

O ativismo judicial nos casos de litigância de interesse público não deve ser utilizado de maneira seletiva, pautada em cunho político, a bel-prazer das funções estatais, não devendo haver postura mais ativa do juiz, mas sim, um policentrismo entre todos os sujeitos processuais, mediante efetivo contraditório e imposição de limites à atual judicial, isso porque

Se a suspeita de que os discursos articulados em torno da necessidade de uma atuação judicial mais enfática nem sempre se voltam para o enforcement dos direitos fundamentais for fundada, a festejada hipótese de que o protagonismo judicial atende ao acesso à justiça será irremediavelmente falsa. Se o "ativismo" puder servir a dois senhores, igualmente à concretização de direitos e à instrumentalização do Judiciário para os projetos estatais ou do sistema econômico, é claro que a tese não passa de uma especulação inconsequente (...) (NUNES et al., 2013)

Verifica-se que a atuação eminentemente passiva do decisor, já em meados do século $\mathrm{XX}$, não era mais capaz de dar resposta efetiva, célere e meritória às demandas judiciais à época, quiçá na contemporaneidade. Entretanto, em que pese todo o movimento de litigância de interesse público ter se desenrolado e fortalecido em um contexto de socialização, que buscava suprir as deficiências do modelo processual anterior, esse novo modelo, inevitavelmente, conduziu a jurisdição a novos equívocos (THEODORO JÚNIOR et al., 2015), a exemplo, o legado do protagonismo judicial advindo da ruptura com as premissas do liberalismo.

O Código de Processo Civil brasileiro de 2015, adjudicando as premissas do Estado Democrático de Direito, traz em seu corpo normativo disposições legais aptas a implementarem, a priori, a utilização de medidas estruturantes, nos seguintes termos:

Uma das bases de perspectiva democrática, trazida no Novo CPC, reside na manutenção da tensão entre perspectivas liberais e sociais, impondo que a comunidade de trabalho deva ser revista em perspectiva policêntrica e comparticipativa, afastando qualquer protagonismo e se estruturando a partir do modelo constitucional de processo, induzindo a convivência de poderes diretivos e gerenciais do 
juiz com uma renovada autonomia privada das partes e advogados (como v.g., na cláusula de negociação processual - art. 190), mediante as balizas do contraditório como garantia de influência (art. 10) e na fundamentação estruturada (art. 489) (...) (THEODORO JÚNIOR et al., 2015)

Portanto, é imprescindível que seja proporcionado ao decisor uma base normativa a fim de que o juiz/tribunal tenha suporte constitucional adequado para, mediante contraditório dinâmico, para que, em conjunto com as partes, fixe medidas estruturantes que sejam capazes de efetivar pronunciamentos jurisdicionais em litígios de direito público, utilizando-se, portanto, das disposições do Código de Processo Civil de 2015, em um primeiro plano, para promover a implementação do processo estrutural na jurisdição brasileira.

\section{IMPLEMENTAÇÃO DO PROCESSO ESTRUTURAL}

As disposições normativas que regulam o Código de Processo Civil de 2015, em um primeiro plano, são hábeis a promover a implementação do processo estrutural na litigância de interesse público para a tutela de direitos fundamentais.

À legislação processualista foram traçadas inovações que se referem à “constitucionalização, à sua estruturação sistemática e aos procedimentos e técnicas de elaboração normativa" (BRÊTAS et al., 2016).

Uma delas diz respeito, justamente, ao disposto no art. 139, IV, do Código de Processo Civil de 2015, denominado como cláusula geral de efetivação ou de atipicidade de medidas executivas, apontando em sua redação

(...) que ao juiz, na condução do processo, incumbe determinar todas as medidas indutivas, coercitivas, mandamentais ou sub-rogatórias necessárias para assegurar o cumprimento de ordem judicial, inclusive nas ações que tenham por objeto prestação pecuniária, o que, bem compreendido, aponta para técnicas inovadoras dentro do direito processual contemporâneo, incluindo-se a possibilidade de o juiz expedir medidas estruturantes para a efetividade do processo (JOBIM, 2017)

Assim, com a regulamentação do art. 139, IV do Código de Processo Civil, ao decisor é ofertada a possibilidade de fixação de medidas aptas a promoverem a 
implementação do pronunciamento jurisdicional exarado, a partir de contraditório, em comparticipação e mediante fundamentação do pronunciamento jurisdicional estruturante.

A cláusula geral de efetividade é uma importante regra a ser utilizada para a implementação de uma decisão estrutural, até porque "manietar o juiz, impondo-lhe a escolha entre apenas duas propostas de solução, é na maior parte das vezes obrigá-lo a cometer injustiças" (ARENHART, 2013).

A grande preocupação, entretanto, gira em torno da atuação judicial desregrada e solipsista, que culmine em um contexto processual intrincado com arbitrariedades decisórias, motivo pelo qual, devem ser impostos limites ao exercício da jurisdição pelo decisor, conforme alertam Lênio Streck e Dierle Nunes, abaixo:

Todos sabem que este dispositivo aumenta o espectro de aplicação do $\S 5^{\circ}$ do artigo 461, do CPC/1973 (atual artigo 536, §1 ${ }^{\circ}$ ) permitindo uma cláusula geral de efetivação para todas as obrigações, inclusive as pecuniárias de pagar quantia, mas que obviamente precisará se limitar às possibilidades de implementação de direitos (cumprimento) que não sejam discricionárias (ou verdadeiramente autoritárias) e que não ultrapassem os limites constitucionais, por objetivos meramente pragmáticos, de restrição de direitos individuais em detrimento do devido processo constitucional. Parece-nos óbvio isso. Sob pena de pensarmos que o CPC simplesmente disse: se alguém está devendo, o juiz pode tomar qualquer medida para que este pague. Ou, como no Mercador de Veneza, de Shakespeare, retirar do devedor uma libra de carne do lado esquerdo do peito, como queria Shylock (STRECK et al., 2016).

Para isso, o art. $489 \S 1^{\circ}$ do Código de Processo Civil traz, a partir de uma fundamentação contrafática, como corolário da democracia, "dispositivo que visa a proporcionar às partes um maior controle acerca das decisões judiciais" (STRECK, 2015) ${ }^{7}$, ao determinar a obrigatoriedade de fundamentação responsiva, determinada, singular, pormenorizada das decisões judiciais, não podendo haver ativismo de qualquer sujeito processual, que deverão atuar sob uma ótica comparticipada e policêntrica.

\footnotetext{
7 “Assim, o CPC/2015 traz uma série de preceitos normativos louváveis que viabilizarão um diálogo mais proveitoso entre os sujeitos processuais coma adoção, por exemplo, do dever do juiz de levarem consideração os argumentos relevantes das partes (Recht auf Berücksichtigung von Äußerungen), atribuindo ao magistrado não apenas o dever detomar conhecimento das razões apresentadas (Kenntnisnahmepflicht), como também o de considerá-las séria e detidamente (Erwägungspflicht)em seus arts. 10 e 489, §1, inciso IV, do NCPC." Cf. NUNES, 2015.
} 
No paradigmático precedente de "Brown vs Board of Education of Topeka", que pleiteava a dessegregação racial nas escolas públicas norteamericanas, a Suprema Corte fixou diversas medidas sancionatórias objetivando o cumprimento da decisão jurisdicional prolatada, propondo, para tanto, graves ameaças à população em caso de desobediência à ordem judicial "como prender funcionários públicos que deixassem de atender suas decisões, soltar presos encarcerados em presídios lotados, bem como fechar instituições públicas que não atendessem aos seus ditames" (BAUERMANN, 2017).

Entretanto, principalmente no que tange à litigância de interesse público, há uma verdadeira mudança da concepção de um procedimento jurisdicional coercitivo para uma ótica comparticipada, ao qual são pilares de sustentação a negociação e cooperação processual $^{8}$ e viga mestra o contraditório como garantia de influência e não surpresa.

Dessa maneira, verifica-se que os dispositivos dos arts. $6^{\circ}$ e $10^{\circ}$ do Código de Processo Civil de 2015, além de se prestarem a impor limites ao ativismo judicial, ainda, são fundamentos à aplicação de medidas estruturantes, a serem fixadas em conjunto com as partes, mediante efetivo contraditório.

Para a tutela de direitos fundamentais a partir da implementação de medidas estruturantes no litígio de direito público, e exemplo, imprescindível se faz a utilização da negociação processual, disposta no art. 190; intervenção da figura do amicus curiae, regulamentada pelo art. 138; a promoção de audiências públicas dos arts. 983 e 1.038; e, ainda, a audiência de conciliação e mediação do art. 334, todos os dispositivos legais do Código de Processo Civil de $2015^{9}$.

Além disso, há de se mencionar a importância da promoção dos diálogos interinstitucionais continuados, reconhecimento das capacidades institucionais dos tribunais e, ainda, a adoção de mecanismos de accountability judicial ${ }^{10}$.

Quanto aos diálogos interinstitucionais, o que deve ser compreendido é que não há uma hierarquia entre as funções estatais, onde uma função estatal vá impor a solução da

\footnotetext{
${ }^{8}$ Para estudo mais aprofundado sobre a cooperação processual, vide ALVES, 2017.

9 “A ideia da cooperação, às vezes, atinge não só as partes mas à própria sociedade, que se faz presente, por meio dos amicus curiae ou mesmo grupos que participam das audiências públicas, que são marcadas quando a questão a ser decidida pelo Judiciário tem grande repercussão social”. Cf. WAMBIER et al., 2015.

${ }^{10}$ Accountability pode ser definida como "a necessidade de uma pessoa ou instituição que recebeu uma atribuição ou delegação de poder prestar informações e justificações sobre suas ações e seus resultados, podendo ser sancionada política, pública, institucional e/ou juridicamente por suas atividades" Cf. TOMIO et al., 2013.
} 
controvérsia à outra, mas sim, em verdade, frise-se, em uma mudança da ótica coercitiva para a comparticipada, haverá uma tentativa de persuasão de uma função à outra, mediante deliberação, acerca do argumento suscitado,

Dessa forma, o Poder Judiciário não atua como um ente meramente reativo e impositivo por meio de suas decisões judiciais. Tampouco o Poder Legislativo se mostra complacente e submisso. Ao contrário, ambos se empenham em maximizar seus desempenhos deliberativos e, assim, persuadir o outro por meio do melhor argumento. A comparação entre a qualidade deliberativa e a legitimidade democrática da decisão de cada um dos Poderes torna-se, assim, mais aferível. Esse jogo não acontece sem conflitos, riscos ou erros. No entanto, ele se mostra não apenas mais genuíno e transparente, mas também mais democrático ao encarar de frente os conflitos e as contradições desse processo, ao invés de se esconder sob retóricas justificativas de supremacia e última palavra. (GODOY, 2015)

Para tanto, devem ser reconhecidas as capacidades institucionais das funções estatais, compreendendo que as limitações de cada ente público são, em verdade, o ponto de partida para a implementação da decisão estrutural, e não seu ponto de chegada, assim,

Levar em conta as capacidades institucionais de juízes e cortes não significa, portanto, negar a possibilidade do controle jurisdicional das leis ou políticas públicas, mas sim levar em conta as limitações naturais da atuação judicial. Repensar a figura do juiz e das cortes a partir de suas capacidades institucionais tampouco implica a defesa de uma atuação completamente formalista ou submissa a discursos pretensamente técnicos alheios ao Direito em detrimento de uma visão crítica e reconstrutiva dos textos normativos. Ao contrário, é a partir do reconhecimento das capacidades institucionais de juízes e cortes que o aplicador pode e deve então buscar realizar a melhor interpretação e aplicação do Direito mediante a coesão dos argumentos utilizados para a sua justificação interna e externa. (GODOY, 2015)

Quanto à accountability, a mesma pode ser classificada sob duas vertentes, a vertical e a horizontal. Sob o aspecto vertical, a accountability é compreendida como a faculdade ofertada aos cidadãos de requererem prestação de informações acerca das ações e/ou resultados do ente público, consistindo, no âmbito judicial, na "possibilidade de os cidadãos controlarem e influenciarem as ações do judiciário", enquanto, sob a acepção horizontal, a 
accountability trata-se da possibilidade de "agentes que podem demandar informações, analisar justificações e sancionar legal e politicamente outros agentes", considerada, na jurisdição, como "controle de juízes e tribunais por outros órgãos judiciários" (TOMIO et al, 2013).

Assim, verifica-se que a adoção de mecanismos de accountability na litigância de interesse público é de sua importância, na medida em que, a accountability, sob as acepções vertical e horizontal, é ferramenta de fiscalidade dos cidadãos para com a função jurisdicional, e da função jurisdicional para com as demais funções estatais, sendo salutar para a aferição de efetividade acerca do cumprimento da decisão estrutural prolatada.

Entretanto, deve-se atentar ao fato de que

Por meio da concepção de governo responsável e pela accountability horizontal, adota-se a idéia e a prática de que um governo dividido é necessariamente limitado. Para exercer suas funções, um poder ou autoridade necessita da ação e da cooperação de outro poder ou órgão, buscando coibir a existência de unchecked power (poder sem controle) (PRZEWORSKI, 1999, apud TOMIO et al, 2013)

No ordenamento jurídico brasileiro, o que se tem de mecanismos concretos para adoção do sistema de accountability judicial ainda é muito precário, podendo ser citadas as ouvidorias judiciais - que, em verdade, constituem um meio híbrido de accountability - e, ainda, os relatórios emitidos pelo Conselho Nacional de Justiça acerca do desempenho dos tribunais o que causa, por curto período, "constrangimento epistemológico" (STRECK, 2011) à função jurisdicional, que, infelizmente, não tarda a passar, devendo, portanto, tal mecanismo de fiscalidade ser sondado e seus estudos aprimorados pela comunidade acadêmica brasileira.

Portanto, em um primeiro plano, a implementação de medidas estruturantes na litigância de interesse público para a tutela de direitos fundamentais, pode ser efetivada a partir das disposições do Código de Processo Civil, abandonando as premissas coercitivas e caminhando em direção a uma ótica comparticipada (art. 10), utilizando-se, a exemplo, da cooperação processual (art. $6^{\circ}$ ), negociação processual (art. 190), cláusula geral de efetividade (art. 139, IV), amicus curiae (art. 138), audiência pública (art. 983 e 1.038) e, ainda, audiência 
de conciliação e mediação ${ }^{11}$, sem perder de vista os limites à atuação judicial impostos pelo art. $489, \S 1^{\circ}$ e a necessidade de promoção de diálogos interinstitucionais, reconhecimento das capacidades institucionais dos tribunais e adoção de mecanismos de accountability judicial. ${ }^{12}$

\section{CONSIDERAÇÕES FINAIS}

A litigância de interesse público, pautada sob a ótica do modelo de socialização processual, buscou afastar-se das premissas do liberalismo jurídico e ganhou especial fortalecimento a partir da segunda metade da década de cinquenta, nos Estados Unidos da América, em decorrência de uma conjuntura de significativas reformas legislativas, prolação de decisões jurisdicionais paradigmáticas - precipuamente, o precedente "Brown vs Board of Education of Topeka" e, ainda, através do alavancamento da temática através de importantes pesquisas acadêmicas.

O modelo jurisdicional de litígio de direito público propõe a solução de controvérsias plurilaterais, que ensejem repercussões complexas, buscando tutelar direitos fundamentais a partir de pronunciamento jurisdicional prospectivo e continuado, construído a partir de efetivo contraditório.

Em que pese a proposição de um modelo de litigância de interesse público configurar um avanço para a função jurisdicional, a mesma não é suficiente, na medida em que, não basta um processo resolver uma questão ímpar que envolva interesse público sem que seja aferida a causa geradora da controvérsia e/ou seja promovida uma efetiva reforma estrutural do ente público através da decisão judicial prolatada.

Assim, devem ser fixadas, em comparticipação, afastando qualquer tipo de solipsismo judicial, medidas estruturantes que sejam aptas a solucionar o caso de interesse público levado à apreciação jurisdicional, bem como, promover uma reestruturação dos próprios entes públicos, utilizando-se, para tanto, os litigantes e o decisor, em um plano introdutório, da base normativa ofertada pelo Código de Processo Civil, a saber, cláusula geral de efetividade (art. 139, IV), amicus curiae (art. 138), audiência pública (art. 983 e 1.038) e, ainda, audiência de conciliação e mediação, sob os pilares de sustentação da

\footnotetext{
${ }^{11}$ Há de se mencionar as "Alternative Dispute Resolution", ou simplesmente "ADR's", agora, denominadas, de meios adequados de resolução de conflitos, a exemplo, a conciliação, mediação e arbitragem. Cf.THEODORO JR. et al., 2013 e NUNES, et al., 2013.

${ }^{12}$ Todos os dispositivos legais mencionados aqui são do Código de Processo Civil: Lei 13.105/2015.
} 
cooperação e da negociação processual (art. $6^{\circ}$ e 190), mediante a viga mestra do contraditório como garantia de influência e não surpresa $\left(\operatorname{art.} 10^{\circ}\right)^{13}$.

Há de se atentar ainda à importante limitação da atuação judicial herdada do socialismo processual, a fim de que a cláusula geral de efetividade não configure uma verdadeira porta aberta à arbitrariedade do decisor, mantendo sempre incólume a aplicação da disposição contra fática do art. 489, $\$ 1^{\circ}$ do Código de Processo Civil de 2015 e a necessidade de promoção de diálogos interinstitucionais, reconhecimento das capacidades institucionais dos tribunais e adoção de mecanismos de accountability judicial, a fim de que, de fato, seja promovida reforma estrutural através da litigância de interesse público para a efetiva tutela de direitos fundamentais.

\section{REFERÊNCIAS BIBLIOGRÁFICAS}

ALVES, Isabella Fonseca. A cooperação processual no Código de Processo Civil. Belo Horizonte: Editora D’Plácido, 2017.

ARENHART, Sérgio Cruz. Decisões estruturais no direito processual civil brasileiro. Processos Coletivos - Revista Eletrônica - Volume: 6 Número: 4 Trimestre: 01/10/2015 a $31 / 12 / 2015$.

ARENHART, Sérgio Cruz. Decisões estruturais no direito processual civil brasileiro. Revista de Processo: RePro, v. 38, n. 225, p. 389-410, 2013.

BAUERMANN, Desirê. Structural Injunctions no direito norte-americano In Processos Estruturais, Salvador: Editora Juspodivm, 2017.

BRÊTAS, Ronaldo de Carvalho Dias; SOARES, Carlos Henrique; BRÊTAS, Suzana Oliveira Marques; DIAS, Renato José Barbosa; BRÊTAS, Yvonne Mól. Estudo sistemático do NCPC (Com alterações introduzidas pela Lei $n^{o}$ 13.256, de 4/2/2016) - $2^{\mathrm{a}}$ ed. Belo Horizonte: Editora D'Plácido, 2016.

CHAYES, Abram. The Role of the Judge in Public Law Litigation, 89, Harvard Law Review. 1281, 1976.

DIDIER JR., Fredie; ZANETI JR., Hermes; OLIVEIRA, Rafael Alexandria de. Notas sobre as decisões estruturantes. Civil procedure review. v.8, n.1: 46-64, 2017.

DIXON, Rosalind; Creating dialogue about socioeconomic rights: Strong-form versus weakform judicial review revisited, International Journal of Constitutional Law, Volume 5, Pages 391-418, Issue 3, 2007.

${ }^{13}$ Todos os dispositivos legais mencionados aqui são do Código de Processo Civil: Lei 13.105/2015. 
EISENBEG, Melvin A., Participation, Responsiveness, and the Consultative Process: An Essay for Lon Fuller, 92 Harvard Law Review. 410, 1978-1979.

FISS, Owen M., As formas de justiça In O processo para solução de conflitos de interesse público, Salvador: Editora Juspodivm, 2017.

FULLER, Lon L., The Forms and Limits of Adjudication, 92, Harvard Law Review. 353, 1978.

GILLES, Myriam, An Autopsy of the Structural Reform Injunction: Oops ... It's Still Moving!, 58,University of Miami Law Review, 143, 2003.

GODOY, Miguel Gualano de. Devolver a Constituição ao Povo: crítica à supremacia judicial e diálogos interinstitucionais. Curitiba: Tese (Doutorado em Direito) - Universidade Federal do Paraná, 2015.

HOROWITZ, Donald L. Decreeing Organizational Change: Judicial Supervision of Public Institutions, Duke Law Journal. 1265, 1983.

JOBIM, Marco Félix, Medidas estruturantes: da Suprema Corte Estadunidense ao Supre Tribunal Federal. Temas de Direito Processual Civil - 5. Editora: Livraria do Advogado, 2013.

JOBIM, Marco Félix; Medidas estruturantes e o 139, IV, CPC. Disponível em: https://www.academia.edu/31357942/Medidas_Estruturantes_e_o_139_IV_CPC__Marco.docx. Acesso em 05 de agosto de 2018.

JOBIM, Marco Félix; ROCHA, Marcelo Hugo da. Medidas estruturantes: origem em Brown v. Board of education In Processos Estruturais, Salvador: Editora Juspodivm, 2017.

MULLENIX, Linda S., Resolving Aggregate Mass Tort Litigation: The New Private Law Dispute Resolution Paradigm, 33, Valparaiso University Law Review, 413 , 1999.

NUNES, Dierle. A função contrafática do Direito e o Novo CPC. Revista do Advogado n. 126 - O Novo Código de Processo Civil. Ano XXXV, maio de 2015. São Paulo: Associação dos Advogados de São Paulo, 2015.

NUNES, Dierle; TEIXEIRA, Ludmila. Acesso à justiça democrático. Brasília: Gazeta Jurídica, 2013.

RESNIK, Judith, Managerial Judges. Faculty Scholarship Series. Paper 951, 1982.

RUBENSTEIN, William B., A Transactional Model of Adjudication. Georgetown Law Journal, Vol. 89, No. 2, January, 2001.

SABEL, Charles; SIMON, William H. Destabilization Rights: How Public Law Litigation Suceeds. Harvard Law Review, 117, 2004. 
SILVEIRA, Daniel Coutinho. Presenting Owen Fiss. Blog Direito e Processo. 9 de dezembro de 2007. Disponível em: http://direitoeprocesso.blogspot.com/2007/12/featuring-owenfiss.html. Acesso em 05 de agosto de 2018.

SOUZA, Fernando Garcia. Política Educacional - Suprema Corte dos EUA - Caso Brown vs Board of Education 347 u.s. 483 (1954) - Julgamento de maio de 1954 In O processo para solução de conflitos de interesse público, Salvador: Editora Juspodivm, 2017.

STRECK, Lênio Luiz. Ministro equivoca-se ao definir presunção da inocência - Revista Consultor Jurídico, 2011.

STRECK, Lênio Luiz. O que isto - decido conforme minha consciência? 5. ed. rev. e atual. De acordo com as alterações hermenêutico-processuais dos Códigos. Porto Alegre: Livraria do Advogado Editora, 2015.

STRECK, Lênio Luiz; NUNES, Dierle. Como interpretar o artigo 139, IV, do CPC? Carta branca para o arbítrio? - Revista Consultor Jurídico, 2016.

THEODORO JÚNIOR, Humberto; NUNES, Dierle; BAHIA, Alexandre; PEDRON, Flávio. Novo Código de Processo Civil: Fundamentos e sistematização. Rio de Janeiro: GEN Forense, 2015.

THEODORO JÚNIOR, Humberto; NUNES, Dierle; BAHIA, Alexandre Melo Franco; Litigância de interesse público e execução comparticipada de políticas públicas. Revista de processo, vol. 224, São Paulo, 2013.

TOMIO, Fabrício Ricardo de Limas; FILHO, Ilton Norberto Robl. Accountability $e$ independência judiciais: uma análise da competência do Conselho Nacional De Justiça (CNJ). Revista de Sociologia e Política, v. 21, nº 45, 2013.

WAMBIER, Teresa Arruda Alvim; CONCEIÇÃO, Maria Lúcia Lins; RIBEIRO, Leonardo Ferres da Silva; MELLO, Rogerio Licastro Torres de. Primeiros comentários ao novo Código de Processo Civil: artigo por artigo. 1 ed. São Paulo. Editora: Revista dos Tribunais, 2015.

YOUNG, Katharine, A Typology of Economic and Social Rights Adjudication: Exploring the Catalytic Function of Judicial Review. International Journal of Constitutional Law (ICON), 2010. 